\title{
A criança no Estado Novo: uma leitura na longa duração
}

André Ricardo Pereira

Universidade Federal do Espírito Santo

RESUMO

Oartigo trata do discurso quejustificou a constituiçáo do programa de proteçãomaterno-infantil lançado durante o Estado Novo, em 1940, a partir da criação do Departamento Nacional da Criança. Sustenta-se aqui a idéia de que ele correspondeu a uma leitura conservadora da metáfora dualista,formalizada no século XVIII, que resultou em demonização do adulto e endeusamento da criança. Para tanto, o discurso é remontado em seus elementos fundamentais e comparado com duas interpretaçóes diferentes sobre o mesmo tema, com as quais se defrontou: a proposta de política social do movimento feminista (dosanos30) euma análise crítica do sociólogo Guerreiro Ramos. Aofim, procura-se demonstrar que elementos inscritos na mentalidade coletiva podem serlidosdemaneiras diversas.

Palauras-chave: ProteçãoMaternoInfantil; Ideologia; Estado Novo.
Abstract

This article analizes the discourse that justified the launching of a chilcare programe by the Estado Novo regime, in 1940, witb the foundatiton of the Departamento Nacional da Criança. I argue that this discourse belonged to a conservative view of the dualist metaphor concerning adults and children bebavior as a struggle between Evel and Goodness, started in the XVIII century. Here, the discourse is depicted into its fundamental elements and compared to two differentes interpretationson the same issue: the feminist moviment project of social care and a critical study by the sociologist Guerreiro Ramos. I argue that simbolic elements of a collective mentality can be read in different uags.

Keywords: Childcare; Ideology; Estado Novo.

Durante o Estado Novo foi instituído o primeiro programa estatal de proteção à maternidade, à infância e à adolescência no Brasil. Seu executor era um órgão do Ministério da Educação e 
Saúde (MES), o Departamento Nacional da Criança (DNCr). Este artigo remonta ao discurso que sustentava tal iniciativa. Curiosamente, apesar de ser produto de uma ditadura, a proposta do DNCr implicava em uma participação ativa da sociedade, ou de certos atores em especial (médicos, professoras, autoridadespúblicas e as mulberes em geral), para que seu fim fosse atingido. Mais ainda, atribuía-se a estes atores uma afetividade natural para com a criança, de forma que bastava boa vontade e articulação nacional (por parte do governo) para que os problemas fossem superados. Pouco antes, o movimento feminista bavia oferecido uma outra proposta, enquanto um estudo técnico financiado pelo próprio DNCr apontava um diagnóstico diferente. Havia, portanto, leituras diferenciadas, mas uma delas foi imposta. Isto se explica, em parte, pelo aspecto conservador do regime, mas também pela longa tradição que associa a infância com a pureza e uma atitude carinhosa. Ao longo do texto, serão apresentados o discurso do Departamento e suas alternativas. Pela comparação, espero demonstrar, que esta instituição, além de sua posição privilegiada no poder, soube articular um antigo conjunto de recursos simbólicos, imprimindo sobre eles a sua interpretação. Esta "engenharia discursiva"também explica sua vitória ${ }^{1}$.

\section{CRIANÇA E AFETo}

O estudo das sociedades consideradas "primitivas" chama atenção, repetidas vezes, para ofenômeno dos rituais de passagem, quando as pessoas deixam a infância e ingressam no mundo adulto. No caso dos homens, é constante o relato da imposição de provas que exigem grande resistência física e coragem. A sensibilidade ocidental se choca com tais práticas, revelando a associação que, bistoricamente, conforme demonstra Phillipe Ariès ${ }^{2}$, e estabelecida entre o afeto e a infância. Trata-se, é claro, de uma construçáo, como tantas outras que caracterizam a "mentalidade coletiva"3 e que só podem existir na "longa duração". São invençóes vividas com tanta intensidade emocional que se torna difícil analisá-las friamente. Omito da pureza na infância é um deles. Mesmo que a realidade desafie suas bases, com exemplos concretos de pequenos seres capazes de crimes bediondos, 
como os meninos assassinos em escolas americanas, como as histórias seguidas de assaltos nas esquinas das grandes cidadesbrasileiras etc, permanece a crença de que tais atitudes vão contra a natureza das crianças. Poroutrolado, nãose estranba a perversidade vinda de um adulto.

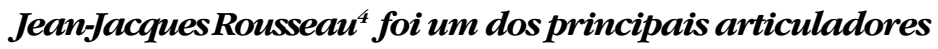
do mito da pureza infantil no interior da cultura erudita. Não é por acaso que ele tenha sido, ao mesmo tempo, um dos três grandes pensadores da tradição contratualista. O recurso simbólico básico desta ideologia estava centrado na dualidade Estado de Natureza x Estado de Sociedade. No exato momento em que as antigas relaçôes sociais de dependência advindas da Idade Média eram abandonadas e substituídas pela noção de igualdade e responsabilidade pessoā, gerando, a nível popular, reinvençóes idealizadas do passado, comofizeram os trabalhadores ingleses estudados por Thompson 6 , Rousseau enxergava o processo com os mesmos olbos de desconfiança. Se "os de cima" e "os de baixo" estavam de acordo com a idéia de que o presente era uma mundo de iniqüidades, o seu contraponto inevitável seria, no espaço, o outro, a figura do selvagem do Novo Mundo; e no tempo, o passado ideal. Se a afetividade havia se perdido no presente, ela existira no passado. Se morrera na Europa, subsistia na América. O passo seguinte seria: se o bomem é mau, a criança é boa. Na mesma época, uma chave dualista de leitura da realidade reforçou visóes acerca do espaço, do tempo e da natureza bumana.

Com o passar do tempo, as transformações sócio-econômicas sepultaram a visão mítica sobre o passado. Na medida em que asforças sociais aprenderam a lidar com os "interesses”, abandonaram a nostalgia pelas “paixões”. Ao mesmo tempo, com o desaparecimento de grande parte dos índios, náo sobrou muito espaço para a associação desta figura com a "pureza original". O mesmo não se deu com a infância. Quando o individualismo se impôs como padráo social, a responsabilidade pelos atosfoi transferida para cada pessoa. Como, desde então, o mal não desapareceu da face da terra, foi fácil demonizar a figura do adulto, transformado naquele que pode ser pessoalmente responsabilizado pelos "caprichos" da humanidade - tais como a fome, a miséria, o crime -ao 
invés de revelar os nexos sócio-econômicos que movem o mundo. É, portanto, a persistência do individualismo que explica a continuidade daquela chave dualista, formalizada literariamente no século XVIII, segundo a qual a criança é pura e o adulto é mau. Sãofaces de uma mesma moeda que modela opensamento sobre o tema. O curioso é que, do ponto de vista de Rousseau, por exemplo, o endeusamento da criança servia ao propósito de melhorar a humanidade. Este argumento original se manteve, mas a custo de muito cinismo, pois, mais uma vez, a realidade veio bater à porta. Quando o espetáculo da pobreza tomou conta dos centros urbanos, crianças e adolescentes pobres começaram a ameaçar a propriedade privada, tornando-se difícil percebê-los como portadores daquela pureza imaculada. É quando surge a figura do "menor". Trata-se de um infrator, de um adulto em miniatura, tão demonizado quanto este ${ }^{s}$. Para manter odualismo, foi preciso afastar a criança do menor. Este processo náofoi racionalmente conduzido. Autoridadespoliciais ejudiciárias, aquelas institucionalmente encarregadas de proteger a propriedade, geraram a figura do menor a partir do papel que lbes foi atribuído e de seus recursos simbólicos. Outros foram os atores encarregados de sustentar o endeusamento da criança, principalmente educadores e médicos (só para citar categorias profissionais). As diferentes posiçóes ocupadas pelos atores permitiram a construção de dois discursos sobre a mesma fase da existência bumana. Isto sófoi possível porque houve uma divisão da realidade em diferentes instâncias e especialidades. Rousseau, ao contrário, tinha clareza da fonte de nossa tragédia, que indicou claramente como sendo a propriedade. Quando ela surgiu, o afeto pelo outro se perdeu. Para ele, o "selvagem" e a criança correspondiam a recordaçóes daquele passado ideal que chamou de "Estado de Natureza”. Ofilósofo, porém, acreditava em uma solução para toda bumanidade, que resolveu chamar de vontade geral, aquela que não é produto do voto, mas que todos conbecemos. É neste ponto que a sua pedagogia fazia sentido, pois a educação cientificamente correta dos filbos, acompanbada de carinbo e afeto, deveria tornar os indivíduos mais capazes de reconbecer esta Vontade Geral, de forma a suplantar os problemas do mundo. 
Oprojeto utópico de Rousseau guardava um pouco da ingenuidade que atribuía a esta face pura dos seres bumanos. Odiscurso atual sobre a criança, por sua vez, é tão mítico quanto o anterior, só que perdeu os recursos simbólicos de uma afetividade desinteressada em troca de um viés mais cínico, calcado na mercantilização da infância. Oprograma assistencialista do Departamento Nacional da Criança, lançado durante o Estado Novo, guardava muito do dualismo original. Isto se deu, em boa parte, pela natureza ditatorial do regime, que impediu a emergência de projetos alternativos e permitiu o reforço de uma leitura conservadora da realidade. Estudar a sua construção, como proponbo aqui, significa, no fundo, compará-lo com a atualidade. Se o conservadorismo daquela época foi, felizmente, superado, seu sucedâneo não é melbor. Enquanto os médicos do Estado Novo achavam que poderiam salvar a infância do Brasil com alguma dose de boa vontade de certos atores sociais, que deveriam se envolver ativamente em seu programa, satisfazemos com a idéia de que podemos comprar a felicidade de nossos filbos com os últimos brinquedos anunciados nos intervalos dos programas de TV eque, com uma contribuição monetária anual ao "Criança Esperança", faremos o mesmo com os filbos dos outros. Durante a ditadura varguista, o discurso ainda era capaz de, supostamente, resgatar nosso carinbo pelo outro. Na nossa bela democracia, dispomonos apenas a pagar para ter a consciência tranqüila. Éjustamente por isso que o que será apresentado a seguir tem um sabor de ingenuidade. Oque interessa não é saber se aquela proposta poderia ter dado certo, mas sim ofato de que o desconforto que nos causa revela uma mudança entre aquele momento e este, revelando talvez uma alteração do nosso modo de sentir que se inscreve no que Vovelle chamou de "duração medianamente longa'?. Este autor se sentia incomodado com a ausência de análises sobre o confronto social nos estudos dirigidos pela concepção de "longa duração". Assim, sem ignorar as permanências, dispôsse a acentuar suas formas de leitura conforme os padróes determinados pela luta de classes. Como Rousseau e os médicos do DNCr, também acreditamos na pureza da infância, mas, ao contrário deles, náo estamos dispostos a nos envolver afetivamente com o 
seu desenvolvimento. Pelo jeito, náo queremos fazer isto com relaçãoanada.

O DISCURSO

O modelo assistencialista do DNCr era baseado na criação de certos equipamentos públicos, principalmente os chamados Postos de Puericultura, onde todas as mães (e não só as pobres) deveriam receber orientação médica desde o início da gravidez, seguindo-se o acompanbamento da criança até a fase escolar, quando entraria em cena a Casa da Criança, que correspondia a um tipo de escola com orientação médica. Tais estabelecimentos seriam supostamente construídos e mantidos por iniciativa local. Ao Departamento cabia dar apenas a orientação técnica e, eventualmente, algum subsídio em dinbeiro. Oprograma, portanto, dependia da boa vontade de certasfiguras sociais que podem ser divididas em três categorias: a) os profissionais: médicos e professoras; b) as autoridades públicas: prefeitos e juizes; c) a "elite moral": os ricos e "especialmente as brasileiras". Outros grupos,

170 como o clero católico, as assistentes sociais, os dentistas etc eram lembrados, mas sem tanta insistência como os anteriores. Quanto aos últimos, tal esquecimento se deve ao fato de serem "técnicos", que ainda precisavam ser formados e náo possuíam grande tradição no campo assistencialista. O clero, por sua vez, era de incorporação mais difícil. Das figuras sociais em destaque sempre se esperava iniciativa, independência e disposição para aceitar as diretrizes vindas da sede do DNCr. O mesmo não se poderia esperar da Igreja. Segue-se um detalbamento da imagem construída para os diferentes atores ${ }^{10}$.

\section{AS FIGURAS}

Apreocupação do Departamento para com o preparo técnico do médico, no discurso que vinba a público, era muito pequena. Com isso, a principal característica do médico seria o seu interesse altruísta pelos outros. A sua presença, mesmo quando não dispusesse de recursos sofisticados de diagnóstico, seria suficiente para garantir a prevenção da doença e da má formação 
corpórea e intelectual. Quando se tratasse da criança, a coisa seriamaissimples ainda.

Partia-se do princípio de que a criança teria uma tendência natural para a cura. Por isso, dever-se-ia evitar o excesso de "drogas", recorrendo-se, muitasvezes, a terapias "naturais"-uma dieta adequada, ar fresco, sol etc-e a perfeita orientação da mãe. Sua ignorância seria o maior obstáculo no caminbo natural do corpo infantil para a sanidade.

O médico era definido como um benfeitor, que acompanbava crianças ricas ou pobres, cumprindo sua missáo principalmente no interior. Esta era uma constante no discurso do DNCr, a figura do "médico da roça". Acompanhando o discurso de ocupação do interior, o médico da roça era comparado a um desbravador. Não podendo ser especialista, deveria cuidar de tudo, mas em especial da obstetrícia e da pediatria. Tal capacidade de iniciativa, porém, deveria ser acompanbada da devida organização, daí a idéia dos Postos de Puericultura. Concebidos como meios para a açãopreventiva, omédico seria suafigura chave. Traballsando de graça, ele daria sua cota para ofuncionamento do Posto, cuja principal vantagem seria manter a mãe com a criança, evitando a lotação de bospitais, que eram vistos como meios mais caros e impróprios à infância, pelo uso excessivo de remédios e afastamentodafamília.

Cabe aqui destacar que a insistência na prevenção, na educação, e em meios informais de tratamento, não devem ser encarados como uma tentativa de enganar a populaçáo, fugindo-se ao compromisso de montagem de uma rede fúsica de atendimento no país sob controle estatal. Os médicos puericultores ${ }^{11}$ seguiam uma tendência dominante em boa parte da elite intelectual de então, segundo a qual a ignorância e o atraso econômico e social se complementavam. "Elevaro núvel de vida" da maioria significava, antes de tudo, impedir que concepçóes erradas circulassem entre as pessoas, ricas ou pobres. Neste sentido, a figura do médico era tida como essencial. Bastava a sua presença para que se desencadeasse a "profilaxia do mal".

Ao erradicar concepçôes advindas da ignorância, o médico permitivia o retorno àquele idealizado "estado de natureza", no 
qual os caminbos da saúde e do perfeito desenvolvimentofúsico e moral seriam dados. Propondo a criação e dirigindo o Posto de Puericultura equipado com um Lactário (unidade para extração e redistribuição de leite materno), o médico estaria estimulando a amamentaçáo ao peito-considerado o mais perfeito alimento para o indivíduo na primeira infância. Trabalhando em estreita colaboraçáo com oPrefeito, poderia sugerirmedidas de saneamento local, evitando a propagação de doenças, tidas como outros elementos desviantes do caminbo natural.

O mais importante, enfim, seria colocar o médico no lugar certo: o Posto de Puericultura mantido por uma associação privada ou por um órgáo oficial, a Junta Municipal da Infância ${ }^{12}$. Em contato direto com a orientação do Departamento, o médico náo encontraria dificuldades em ver sua palavra acatada por todos, "porque todas as suas açóes visam apenas o bem do próximo, de quem se torna o amigo dedicado e solícito de todas as horas".

Passemos à segunda figura de destaque, a professora. Esta era vista, a priori, a partir de sua condiçãofeminina. Moldada 172 para a dedicação ao outro, de forma semelbante ao médico, o mais importante não seria o seu preparopedagógico, maso esforço de sua presença e o uso de sua autoridade. A sua atividade náo deveria se dirigir diretamente para as máes, maspara as crianças, no ambiente estrito da sala de aula ou no espaço circundante maior da escola e de suas ligaçóes com o resto da comunidade. Mais uma vez, o esforço individual se encadeava com o movimento da organização. Bastava, portanto, boa vontade e iniciativa.

Aprofessora deveria, antes de tudo, estudar puericultura nos tratados ou mesmo nas publicaçóes do DNCr. Os conbecimentos adquiridos deveriam ser repassados aos alunos de forma conveniente, com especial destaque à divisáo entre o que se dirigia aos educandos como um todo-noçóes de bigiene, de comportamento, recreaçáo etc-e o que era específico para meninos e meninas: o preparo do futuro chefe de família e da máe.

A professora deveria tomar parte nas Juntas e nas associaçóes privadas de assistência, onde, no entanto, seria apenas mais uma peça. Era no ambiente institucional de escola que sua ação se multiplicaria. Aí, deveria promover várias iniciativas: a caixa 
escolar, a cooperativa de alunos, a merenda escolar, o centrocívico, o conjunto teatral, oclube de pais e mestres, o chube agrícola e uma organização proposta pelo Departamento: a Bandeira de Saúde.

Todas essas coletividades teriam o objetivo de promover a assistência, mas principalmente "modelar astendências dos alunos, estimulando as boas e protegendo-os das más”, que derivariam da ignorância, o “desvio” bistórico do bomem brasileiro. Mas aqui entrava um elemento complicador: a relaçáo conflituosa entre comportamento moral e condiçáofísica. O princípio do mens sana in corpore sano era entendido dentro de certos limites, já que o ser bumano, uma vez afastado dos efeitos maléficos da ignorância, se transformaria num produto bruto, um diamante a ser lapidado. Bem de acordo com o modelo do estado de natureza, reduzido às paixóes naturais, o ser bumano tenderia a se afastar da barmonia e da coesão social. Daí a necessidade de uma "profilaxia moral" que acompanhasse a intervenção médica.

Assim, a professora, atuando também de preferência no meio rural, poderia cumprir sua parte no grande projeto de organização social. Para ela eram dirigidas publicações especiais e o DNCr propôs a constituição de uma estrutura escolar, constante de um estabelecimento conbecido como Casa da Criança, onde ela se incluiria, achando seu espaço e razáo de ser.

A terceira figura era a do prefeito, sempre visto como autoridade pública estratégica nas preocupaçóes dos médicos puericultores do MES. Em contrapartida, jamais se fazia referência à atuação de interventores ou mesmo presidentes de Estados. Isto se devia a um antigo conflito com as autoridades sanitárias estaduais, que não reproduzirei aqui. Basta que se saiba que, durante o processo de ascensáo burocrática dos médicos puericultores na estrutura do MES, as autoridades de saúde nos Estados negaram-se a aceitar a orientação proposta a partir da capital do país. Preferiam manter a assistência à infância dentro das antigasnormas de tratamento ambulatorial, sem criar unidades específicas para tal fim. Assim, o Departamento resolveu ignorar as instâncias estaduais e apelar diretamente aos municípios, porém, mais uma vez, seguindo a lógica da iniciativa pessoal. O DNCr não esperava que os prefeitos criassem repartiçóes municipais espe- 
cíficaspara a infância, com oque as prefeituras acabariam oneradas e se abriria uma brecha para o vício do "burocratismo".

Seguindo o raciocínio aplicado à rede pública de bospitais, não seria necessário criar um aparellbo estatal que, por si só, nada faria. Os prefeitos deveriam lançar máo de outro recurso: o envolvimento direto das elites locais no dever social da proteção materno-infantil. Isto se faria pelo estabelecimento da Junta Municipal da Infância.

AJunta era proposta peloDepartamento como um pequenogrupode "pessoas importantes" dolugar, nomeadaspeloprefeitoa título bonorário. Elas deveriam se reumirpara estudar amellsormaneirade seorganizar a proteçãomaterno-infantilnommicípio. Eleseriapresidida pelo prefeito ou pelojuiz (de menores, se bouvesse).

AJunta obteria recursosfinanceiros, daprefeitura ou de particulares, distribuindo-os entre as instituiçóes oficiais e privadas. Cada Juntadeveria teruma oumaisvigilantesremumeradas, encarregadas de investigarcasosdecriançasoumães desamparadasmoraloumaterialmente. Da intervenção desta vigilante - uma assistente social na maior parte das vezes-seria possível resolver problemas de abandono, principalmente quando redundassem de desajustesfamiliares, ou seja, fatores que eram encarados como de ordem comportamental, sem demandar, portanto, custosmateriaismaissignificativos.

Nos municípios maiores, aJunta poderia ter um diretor remunerado, indicado pelo seu presidente. Este diretor seria responsável pelas atividades executivas: a) prestar assistência a órfãos, abandonados, ilegítimos etc; b) prestar assistência às mães miseráveis; c) fundar e fiscalizar obras de assistência materno-infantil, principalmente Postos de Puericultura; d) organizar caixas de socorro para atender a casos de urgência.

AJunta, portanto, tornava-se oóngáo corporativo por excelência. Criada a partir de uma lógica de cooperação social, ela deveria penetrarno aparellbo estatal, ganhando recursos públicos, livrando a prefeitura de despesas desnecessárias, ejamais existindo sem a presença da autoridade pública como seu “animador”. Oprefeito, como braço do DNCr, garantivia a participação da elite local.

A quarta figura em destaque era a dojuiz; um personagem de assimilação mais difícil, justamente por causa da citada divi- 
sáo entre crianças e menores. Durante o Estado Novo, porém, o aparecimento do Departamento produziu uma situaçáo nova de legitimidade para incursóes da puericultura nos problemas dos menores. Alenta expansão dosjuizadosprivativos de menorespelo paús, juntamente com a pequena e tardia coordenação das obras assistenciais para “abandonados”, que só adquiriu vulto com o estabelecimento do Serviço de Assistência a Menores (SAM), em novembro de 1941, deu espaço para que o DNCr tentasse trazer os juízes para sua área de influência. Daíque asJuntas também pudessem ser presididas por eles. Todavia, os interesses já estavam por demais estabelecidos, seja na prática seja no campo discursivo, para que bouvesse incorporação pura e simples. Os médicos puericultores teriam que investir mais no campo da assistência a menores, transformando-o num problema de "bigiene social", para que viessem a ter alguma influência neste campo ${ }^{13}$.

Agrande novidade da interpretaçáo dadapeloDNCrànatureza da assistência social, maturada durante os anos 30 e lançada com grande esforço propagandístico durante o Estado Novo, foi a idéia de que os desviose as carênciasnão atingiam apenas a pobres, mas a todas as pessoas. A correção das deficiências morais e materiais contribuiriam para estabelecer a táopropalada "democraciasocial", que o regime propunha como sua tarefa mais importante.

Ademocracia social referia-se a uma situação ideal em que todos poderiam desenvolver suas capacidades sem que isto implicasse em desequilíbrio, ou seja, transferência, pormeios considerados injustos, do produto do trabalbo-riqueza material "espiritual" e intelectual-para outros grupos. A constituição deste projeto político partiu da constatação de que tais desequilibrios existiam e apenas o Estado poderia promover a redistribuição entre todos os setores de forma pacífica e coordenada. Somente assim os padróes comunitários de uma sociedade coesa poderiam ser alcançadosna dimensão maior da nação.

Do ponto de vista do programa do Departamento, implementar a democracia social significava restituir a posiçãode segurança das crianças e de suas famílias. Portanto, quem dispunba de recursosmateriais e morais deveria dispendêtlosnesta tarefa. Neste ponto da argumentação encaixavam-se os ricos e as mulberes. Antes de 
seguir, faz-se necessário afirmar que a questão não era tratada a partir de uma lógica de redistribuição de renda, quer dizer, situação resultante da exploração do traballbo, mas sim de normalização das relaçóes entre todos. Daíque não se defendesse a proposta de taxação pelo Estado para investimento em políticas compensatórias. No discurso, o Estado deveria estimular os mais afortunados para que auxiliassem os demais a assumirem sua parte no todo do que estava disponível.

No que se refere aos ricos, o Estado deveria dirigir-lhes uma campanba propagandística específica, com o objetivo de modificar sua atitude de indiferença. Supunba-se que tal indiferença derivaria não de sua natureza, mas do desenvolvimento do "industrialismo", de uma sociedade urbana e liberal, onde cada um seria estimulado a ter um comportamento individualista. Com a cruzada cívica iniciada pelo regime, porém, uma atitude de maior solidariedade poderia suplantar as atitudes "artificiais".

Afigura da mulher, por sua vez, era elaborada de uma maneira mais difusa. No que se relacionava com o seu papel noprojeto

176 dademocracia social, a identidade era construída em torno da "senhora" e não da mãe. Esta era objeto, aquela era instrumento da política. Isto seria possível pela sua natureza bumana e por sua disponibilidade, ou seja, o que tinham a mais e poderiam oferecer.

Adisponibilidade da "senbora" teria uma função especial no andamento dos trabalhos do Posto de Puericultura. Em primeiro lugar, as senhoras trabalhariam na organização de uma associação de proteção materno-infantil, que, com o apoio da Junta, construiria e manteria o Posto. Em segundo lugar, elas atuariam nos seu serviços. Antes mesmo da inauguração, deveriam fazer propaganda do Posto, visitando as casas com muitos fillos, de forma a convencer as máes sobre a importância da assistência e da prevençấo. Nos dias de visita, as senhoras receberiam as mães com seus filbos logo na entrada do Posto, acolbendo-as "alegremente" e mostrando interesse pelas crianças. Na falta de um funcionário, deveriam preencher a fich a de atendimento, tomando nota de todas as recomendaçóes do médico, para reforçá-las depois, na bora da saída, quando a mãe seria exortada a retornar em 
prazos fixos-quinzenalmente quando com bebês, e mensalmentepara as criançasmaiores.

Mas a incorporação das "senboras" ganbaria um competidor, com o advento da Legião Brasileira de Assistência (LBA), em 1942. Desde o início, sua atuação junto ao DNCr foi bastante intensa, a ponto de realizarem projetos em conjunto. Todavia, o projeto da LBA seguia um caminbo próprio, devido à sua vinculação política com a primeira-dama e uma noção maistradicional de assistencialismo dirigido aos pobres. De qualquer forma, entretanto, não resultava em perigo para o discurso do Departamento, que, neste nível, só poderia ter sido ameaçado pelas propostas da Federação Brasileira para o Progresso Feminino, que teve sua voz calada pela ditadura.

Em resumo, preservar a saúde da criança pela manutençãoda estabilidade de sua família implicava na constituição de meios que executassem esta dupla tarefa, promovendo, ao mesmo tempo, a integração social. Para tanto, os meios físicos deveriam propiciar a assistência material-atendimentomédico, distribuição de alimentos etc-e moral-educação das mães e das crianças-, orientadas pelo Estado e contando com a participação de quem já tinha tais problemas resolvidos. Esta dupla tarefa conduziria à constituição de dois tipos de organismos: aqueles mais diretamente ligados à assistência material eoutros à assistência moral, sem desconsiderar que os dois deveriam caminharjuntos. Ou seja, uns estabelecimentos seriam médicos e outros, educacionais. Entre os primeiros, destacavam-se os postos de puericultura, os lactários, as gotas de leite e asmissóes da infância feliz. Entre os segundos, eram previstas: as escolas maternais, as escolas primárias, osjardins de infância, os parques infantise as casas da criança.

\section{OS MEIOS DE ATUAÇÃO}

Mesmo no campo da ação mais “técnica” o discurso produziu opções que eram claramente baseadas nos pressupostos gerais que vêm sendo delineados. Oprimeiro exemplo é o do planejado serviço de Assistência Obstétrica Familiar. Por seu intermédio, seriam realizados partos nas residências. Já que bavia poucas vagas nas maternidades mantidas pelo Estado e pelas instituições 
particulares, sempre que possível, oparto deveria ser feito no lar. E mais importante, considerava-se inconveniente que a mãe se ausentasse de casa, com os filhos sendo distribuídos entre os parentes e o marido abandonado, sem refeiçóes, roupa lavada $e$ passada etc. Mantendo-se a mãe em casa, o ambiente familiar não seria abalado, mesmo no seu período de "resguardo".

Tal serviço deveria funcionar em todos os Postos de Puericultura, na medida em que haveria ali parteiras habilitadas, prontas a se dirigirem às casasquando solicitadas. Todavia, sóbánotícia de serviço semelhante efetivamente funcionando em um órgão do DNCr, o Instituto Nacional de Puericultura, localizado no Rio de Janeiro.

O segundo exemplo é o das Gotas de Leite. Sua função seria a de distribuir leite entre as mães necessitadas. Isto deveria ser feito, a rigor, pelo Lactário, independente ou como parte do Posto de Puericultura, mas este era pensado com um sentido didáticomais amplo: entregar leite e ministrar ensinamentos sobre amamentação para todas as mães, independente de classe social. A “Gota" era mais claramente ligada ao assistencialismo para com 178 mães pobres, cuja origem se encontrava na República Velha. $O$ Departamento tentou dar-lhe um sentido novo, mas a realidade da pobreza e do status social falaram mais alto e a "Gota”, concretamente, manteve seu sentido original. Veja-se:

OInstituto Nacional de Puericultura mantinba uma "Gota". Sua existência era justificada em função da necessidade de se substituir o serviço de amamentação "mercenária"-uso de amas de leite - por um método mais seguro e bigiênico. Além de corresponder a um alimento cientificamente balanceado, quando a máe náo podia amamentar, o leite esterilizado evitava que o emprego da ama resultasse em prejuizo para seu próprio fillbo. As doadoras recebiam uma certa quantia em dinbeiro por litro de leite extraído, mas ofilbo não deveria ter menos de dois mesese também seria acompanbado, de forma que a venda do leite não atrapallsasse a alimentaçãoda criança. Oleite doado era pasteurizado, para que se pudesse evitar a adição de leite de vaca a este, com o que o produto ficaria talbado. Isto, provavelmente, era prática comum das mulberes pobres que recolbiam o leite ali, tentando alimentar os demais filbos. 
SegundooDNCr, qualquer um poderia estabelecer uma "Gota", bastando para isto apenas o capital inicial. Quando estivesse em plenofuncionamento, poderia vender $2 / 3$ doleite para particulares pelo dobro do que pagava às doadoras. As doadoras e o pessoal técnico receberiam pagamento, maso médicopoderia abdicar dele emfavor do bem público. Resta saber se asmães de classe média, na prática, nãoprefeririam contratardiretamente as amas, comovinham fazendo desde tempos coloniais, enquanto as pobres recorriam ao serviço pela impossibilidade de fazer o mesmo.

Ainda na questão da pobreza, as chamadas Missóes da Infância Felizforam pensadas como iniciativas, mais uma vezmantidas localmente, que visassem a distribuição de alimentos balanceados às crianças pobres. Tais refeiçóes seriam complementarese acompanbadas, como sempre, de orientação às mães sobre o que prepararpara os fillos.

Passando para os projetados estabelecimentos educacionais, os componentes conservadores do discurso tornam-se mais evidentes. Supunba-se que manter a estabilidade da família significava suprir suas deficiências e estimular sentimentos e bábitos que valorizassem o grupo como referência básica da identidade social. Neste caso, o indivíduo deveria ser educado para ver na família, nos amigos, na vizinbança, na pátria, que seria a família estendida, a sua razáo de ser. Para tanto, o Posto de Puericultura náo estaria capacitado. Seria necessário criar estabelecimentos que recebessem a criança enquanto a mãe fosse trabalbar, de forma que, pelo menos assim, a estabilidade econômica pudesse ser garantida, e, ao mesmo tempo, a educação da criança 'física e moralmente sadia"fosse realizada.

O programa educacional do Departamento baseava-se na expansão de objetivos pela qual passara a puericultura desdeo período da República Velha, quando a ciência se preocupava com a concepção, gestação, primeira e segunda infâncias. Agora, a terceira infância fora incorporada, surgindo também uma puericultura "social", quer dizer, a mobilização em favor do projeto de bem criar os “filbos da Nação". Isto derivava, sem dúvida, do avanço ideológico de concepçóes políticas autoritárias, tanto no Brasil quanto na Europa, de onde a puericultura provinba. Esta origem 
também explica uma preocupação nova: a educação não só no ambiente familiar e na escola como também nos momentos de lazer. A recreação infantil deveria ser orientada, o que refletia problemas específicos de crescimento urbano e do alargamento da classe média, o que não era tão premente no Brasil. Mesmo assim, este aspecto foi incorporado, com grande entusiasmo, no programa do DNCr, talvez porque se encaixasse bem no objetivo de generalização da política para todas as classes, com o que o discurso tocava a invejada classe média urbana brasileira.

Énas iniciativas educacionais, portanto, que o Departamento demonstrava mais claramente o tipo de família que esperava, com o auxílio de sua intervenção, generalizar: a de classe média. Neste modelo ideal, o marido trabalhava, era o "chefe". A mãe ficava em casa, cuidando do lar e da educação dos filhos. Estes permaneciam na escola até que estivessem prontos para trabalbar pelo país, ocupando seu interior e produzindo as riquezas mal exploradas.

O trabalbo feminino era visto como o maior do obstáculo para a realização do objetivo. Mas a imagem da mulher que traba-

180 Ihava era cuidadosamente construida, de forma a transformar a questão em um problema pessoal. Isto implicava numa certa leitura da realidade do campo-onde se encontrava a maior parte da população-e da cidade.

A perspectiva que se tinha da vida familiar no campo era a de equilibrio e imutabilidade. Na pequena propriedade ou nafazenda dirigida por um proprietário "generoso", otrabalbo, tanto do marido quanto da esposa, seria realizado nas imediaçóes da casa. Supunha-se que o seu produto revertia, pelo menos parcialmente, para a família, numa espécie de economia fechada, onde o Estado deveria interferir apenas para resolver os problemassanitários e prover educação básica. Logo, o trabalbo da mulber no campo era visto como complemento das tarefas domiciliares.

Na cidade, a visáo se dividia entre três grupos: ooperariado, os "pobres" e a classe média e alta. No primeiro caso, partia-se do princípio de que a mulber operária, ou seja, aquela que trabalbava em estabelecimentos industriais, era protegida pela legislação a cargo do Ministério do Trabalho, Indústria e Comércio (MTIC). 
O Departamento via os problemas maternais da operária como de responsabilidade do MTIC. No máximo, fazia sugestóes, como a de que se estabelecessem o seguro-maternidade, nos moldes, aliás, do que havia defendido o movimentofeminista, como responsabilidade das Caixas e Institutos de Aposentadorias e Pensões. Curiosamente, o Departamento não se apercebeu sequer do campo aberto, desde 1940, pela atuação dos Sindicatos, que poderiam utilizar parte de suas verbas para serviços de assistência materno-infantil, possivelmente devido à importância secundária que a operária tinba no seu discurso.

A mulber pobre fazia parte daquele grupo indefinido entre a marginalidade e a ocupaçấo de tarefas "bumildes”. A mulher pobre era, de forma estereotipada, a empregada doméstica, eternamente à mercê dos perigos de se tornar, devido à sua suposta ingenuidade, mãe solteira. Oseu lar era tido como inevitavelmente instável e o seu fillbo um abandonado, material e/ou moralmente. Aqui, oproblema transmutava-se para a figura do menor abandonado. Não tendofamília, oEstado iria provê-la pormeio de instituições específicas.

Oolhar sobre a família de classe média era suficientemente amplo para inchuir tanto a classe trabalhadora-o maridopodia seroperário, mas a esposa ficava em casa-quanto os funcionários públicos e os profissionais liberais. Neste caso, o único tipo de ocupaçãofeminina lícita era a de professora primária. Esta familia deveria viver numa casa própria, localizada num bairro de tipo babitacional. Era para ela que os estabelecimentos educacionais do DNCr se dirigiam, em cidades grandes ou pequenas. Este modelo de família estaria espalbado por todo país e abrigaria a maior parte das pessoas. O que não se adequasse a ele, seria exceção, minoria ou desvio.

A mulber de classe média, por questóes puramente individualistas, como a busca por maior "conforto", ou por um desequilibrio momentâneo do orçamentofamiliar, poderia resolver traballbar: A solução mais efetiva para tal empecilho à boa educação dos fillbos seria proibir o trabalbofeminino, oque, "infelizmente", mostravase impossível (principalmente diante da orientação maior do regime de valorização do trabalbo em geral). Daí a necessidade de 
intervenção do Estado, criando estabelecimentos para os quais as criançasseriam dirigidas enquanto asmãesnão estivessem em casa, reproduzindo um verdadeiro "ambiente familiar".

No que se refere à mulber de classe alta, o Estado deveria realizar uma campanha nosentidode sensibilizá-la para que abandonasse a vida social intensa, asfestas, as viagens etc. Sem problemas econômicos, bastava que permanecesse em casa nos momentosnecessáriose, nos demais, se engajasse nas obras assistenciais. Assim, contribuiria para a formação da futura elite dirigente e para o crescimento populacional do país.

Os estabelecimentos educacionais imaginados para a classe média eram: a creche, a escola maternal, ojardim de infância, o parque infantil, a escola primária e a casa da criança. Segue-se a forma como eram concebidos.

Acreche seria olugar destinadopara receber crianças até dois anos. Devido ao papel da amamentação e a crítica ao traballbofeminino, este tipo de recurso só era considerado correto para as operárias, oque, a propósito, era garantidopelas leistrabalbistas.

182 Daíofato de mal se falar em creche no programa do Departamento. A sociedade náo era estimulada a criá-las e não bavia textos sobre seu funcionamento. Apenas se destinavam alguns recursos para as que já existiam, geralmente por intermédio da LBA.

A escola maternal deveria receber crianças de 02 a 04 anos. Sua existência era justificada pelo fato de que a "vida moderna" privaria um bom número de crianças de elementos indispensáveis para o estímulo do desenvolvimento fúsico e formação de uma personalidade equilibrada. Para que tais objetivos fossem alcançados, justamente nesta faixa etária, a criança deveria ter espaço, "arlivre”, onde pudesse exercitar suas atividadesmotoras, junto de companbeiros para brincar, de forma que pudesse ter acesso aos "rudimentos da noção de comunidade".

No entanto, nas grandes cidades, a vida moderna teria assentado as pessoas em pequenos apartamentos ou em casas sem jardim/quintal, privando a liberdade da criança, e, mais ainda, diminuindo o tamanbo da família para um ou dois filbos, o que teria agravado a falt a de companbeiros. A mãe, precisando trabalhar, teria entregue a educação dos filbos a empregados incompeten- 
tes ou parentes. Neste caso, o sentido original da família nuclear se perderia. Em qualquer circunstância, a criança se tornaria "nervosa" e teria seu desenvolvimento atrapalhado.

A escola maternal deveria resolver tal dificuldade. Imaginada como uma casa no centro de um grande terreno, a criança deveria passar ali entre 06 ou 07 boras por dia, almoçando, dormindo por duas horas e tendo atividades fisicas orientadas por professoras especializadas, as suas “mães modelos".

Além da socialização e do trabalho físico, a escola maternal propiciaria uma ambiente de carinbo, no qual a professora substituiria a máe, mas seria auxiliada por outros profissionais, comoo médico, que examinaria todas as crianças na entrada, separando as doentes das sãs. Aquelas seriam dirigidas a uma dependência especial, para receber tratamento adequado. As outras deveriam trocar de roupa e ir para a sala de brinquedos ou jardim, onde teriam acesso brinquedos adequados para sua idade e desfrutariam de jogos em conjunto com os companbeiros.

A escola maternal estaria equipada, portanto, com sala de brinquedos, sala de repouso, cozinba dietética, banbeiros, rouparia, jardim, solário, sala do médico e isolamento. Sua direção seria entregue a uma mulber com conbecimentos de bigiene infantil, psicologia e educação. Haveria também "dietista", atendentes e serventes.

Crianças de 04 a 07 anos seriam levadas para ojardim de infância, onde continuariam a brincar, mas já com a introdução de rudimentos de educação formal, como o reconbecimento do alfabeto, dos números e a silabação. A grande diferença estaria nofato do jardim de infância náo ser destinado apenas aos fillhos de mulberes que trabalbassem fora de casa. Todas as crianças deveriam freqüentá-lo, pois o processo educativo se iniciaria ali, com o emprego de professoras especializadas, classes ao ar livre etrabalhosmanuais.

Já oparque infantil se destinaria a crianças em idade escolar, devendo ser ocupado nos momentos de folga das aulas. Ele poderia ser isolado ou estar em conexáo com os anteriores. Quando isolado, além da recreação, deveria assumir também funções educativas e bigiênicas. Para tanto, estaria localizado, de preferência, nos bairros de população concentrada. O modelo padrão 
contaria com $4000 m^{2}$ de terreno plano, de terra batida, cercado com pequenos arbustos e com uma parte coberta-uma miniatura de ambiente natural, em contraposição ao "artificialismo" da cidade-sendo isto suficiente para atender a 300 crianças. Propiciaria também exames médicos e assistência alimentar. Para sua direção, dever-se-ia dar preferência a professoras de educação física. Todos os aparelbos seriam cuidadosamente distribuídos.

Ainda no campo das instituiçóes educativas, nota-se que, para os médicos puericultores, a escola primária deveria deixar de ser um aparelho meramente instrutivo e se transformar num "sistema plasmador de personalidades ajustadas e produtivas". Isto significava que a escola deveria abandonar a atitude de formar uma criança sadia, bonesta e conbecedora, masincapacitada para encarar o mundo real quando chegasse à maturidade. Para preparar cidadãos adaptados a um mundo em mudanças, a escola deveria desenvolver as seguintes atividades:

I) Promover a melhoria social dos alunos: por meio de caixas escolares, por exemplo;

II) Providenciar assistência física: com tratamento médico, merenda etc;

III) Garantir assistência educacional, com os seguintes aspectos;

IV) Fúsico: ginástica, jogos etc;

V) Emotivo: com jogos educacionais que produziriam autocontrole;

VI) Sanitário: ensinar bigiene;

VII) Intelectual: a educação tradicional;

VII) Moral e cívico: a integração na comunidade representada pela Nação, o que poderia ser feito pelo escotismo;

IX) Religioso: na qual o estado náo deveria intervir, mas que deveria existir;

X) Recreativo: dança, canto, literatura etc; 
XI) Administrativo: ao participarna organização de chbes, grêmios etc;

XII) Econômico: pelo estímulo à posse de uma caderneta na Caixa Econômica em nome da criança, pela exposição de trabalbos das criançaspara venda etc;

XIII) Agrícola: ensinando a criança a ter canteiros de legumese verduras para a merenda escolar ou comofonte de renda para a Caixa Escolar.

Quer dizer, qualquer espécie de atividade que implicasse em trabalbo em grupo, divisão de tarefas, cooperação com fins objetivos, resultando na obtenção de algum produto material deveria ser a tômica da escola. Isto prepararia um cidadão voltado para o grupo e produtor de riquezas, consciente de sua posição social e de seu papel, fosse ele profissional ou sexual, no que se incluía a preparação do marido eda esposa.

Essas preocupações afastavam aspectos ligados ao conteúdo pedagógico e à formação técnica em si, em parte pelo sentido que se procurava dar e em parte porque se esperava que tais problemasfossem resolvidos em outros níveis escolares. Como não bavia intervenção do governo federal no ensino primário-só definida na Lei de Diretrizes e Bases do Ensino Nacional, de 1961 -os médicos encontraram espaço suficiente para especular sobre estabelecimentos educacionais apropriados àsregras da puericultura, pois as definições sobre currículos não estavam fechadas.

Por fim, o Departamento projetou uma instituição que reuniria todos os estabelecimentos em um só: a Casa da Criança. Em um grande prédio seriam agrupadas a creche, a escola maternal, ojardim de infância, a escola primária, oparque infantil, oposto de puericultura e, possivelmente, um abrigo provisório para menores, além de um clube agrícola, para o ensino do uso da terra.

Mais uma vez, como no caso de todas as outras instituições do programa do DNCr, ofinanciamento partivia dos particulares e do Estado em conjunto. Daí tantos projetos serem apresentados. Conforme as possibilidades, cada um seria executado em seqüência. Mas até neste aspecto dever-se-ia desenvolver uma ação 
educativa, reforçando a idéia de doação e o compromisso que isto implicava.

O nosso sentimentalismo e o bábito de fazer caridade às cegas induz a maior parte destas instituiçóes a prestar os seus serviços gratuitamente a todos os que a elas recorrem. Essa prática deve ser modificada. É indispensável cobrar uma pequena mensalidade, ou talvez melhor uma quota semanal a todas as mães que depositam os filhos para poderem trabalhar. A tarefa de cuidar dosfilbos é para elas uma estrita obrigaçáo. Declinando dela para ir ganbar dinbeiro, ficam no dever de pagar a quem as substitui. É muito comum entregarem elas os filhos a pretensas criadeiras, que Ihes cobram altas mensalidades, e, ignorantes ou sem consciência, sacrificam às vezes irremediavelmente as pobres crianças. “(...) é sabido que prezamos mais aquilo que nos custa trabalbo e dinbeiro, do que tudo quanto obtemos de graça. (...) $O$ dever de pagar serviços prestados é um princípio moral social que deve ser praticado sempre que possível, no próprio interesse da dignidade pessoal do beneficiado".

186 Tal pagamento, porém, náo seria suficiente para reaver o investimento em prédios, materiais nem para a remuneração do médico, que, como sempre, traballharia por consciência do dever social. O pagamento, então, cancelaria a idéia de caridade e a suposta prática do "abuso" da caridade, introduzindo a noção de custo e a impossibilidade de seu efetivo ressarcimento. Daí o compromisso moral da elite para com o povo, que deveria retribuir cumprindo sua parte na tarefa de crescimento populacional, de ocupação do interior e de desenvolvimento da Nação.

\section{UM QUADRO GERAL}

O discurso dos médicos puericultores nunca foi de todo sistematizado. Havia, entretanto, alguns elementos simbólicoscomuns, implicitamente presentes em cada proposta que o DNCr formalizava em suas publicaçóes. Do ponto de vista mais geral, traballbava-se com aquele dualismo que opunba Cidadex Campo, equivalente ao confronto entre Artificial x Natural e Indivíduox Coletivo. Oprimeiro pólo era sempre mal visto, enquanto o segundo correspondia a uma condição a ser restaurada. Apesar dos enun- 
ciadores do discurso terem sido quase todos médicos, portanto, profissionais formados na tradição do avanço e da evolução do saber, pelo menos em seus aspectos técnicos, afastando-se desse passado idealizado, odualismo estava tão arraigadonassuas idéias que chegava a haver mesmo um menosprezo da prática instrumental da medicina. A criança era o passado do adulto, este pólo mais antigo, ingênuo, natural. Ela teria uma tendência natural à cura. Bastava que recebesse a alimentação adequada e vivesse em um ambiente que fugisse a todo artificialismo, o que significava, no fim, estimular seu envolvimento com outras pessoas. Para garantir este tipo de coisa, havia dois tipos de intervenção a serem realizadas: uma mais científica e outra ética, mas não de todo separadas. Quem cuidasse da criança deveria estar babilitadoe, ao mesmo tempo, carregar o afeto e a dedicação necessáriospara que todo universo natural pudesse ser reestabelecido. Daí a idéia de que a intervenção do Estado deveria ser mínima. Em primeiro lugar, por razóes práticas, já que a constituição de um aparellbo burocrático grande eratida como custosa e ineficiente. Maisimportante, porém, é o fato de que, no discurso, o Estado teria como sua contrapartida a Sociedade, aquele campo de "artificialismo" do qual se pretendia fugir. ODepartamento queria que as pessoas cuidassem das crianças. A coletividade coesa, fundada na familia, seria o melhor contraponto para a natureza. Mas o mundo náo possuía tal face. A solução estaria no laço corporativo entre Estado e aquelas figuras sociais que, por sua natureza, seriam capazes de lidar com as crianças. Assim, o lema era: o Estado orienta e as pessoasfazem.

O naturalismo era um elemento estruturante do discurso. Tudo deveria ser feito no sentido de redirigir as atençóes para o grupo bumano básico, a família. Partos deveriam ser feitos em casa, para que a família não se desagregasse. A mãe deveria amamentar a criança, para evitar a introdução de uma figura externa, a ama de leite. A máe não deveria trabalhar, para ter tempo e se dedicar aos filhos. Havia, implicitamente, um ideal de estabilidade de familia que, refletia uma imagem idealizada da família européia de classe média; nada mais urbano do que isto. Porviastortuosas, o discurso, que começou com um ideal de natureza, retornou 
à sociedade. Nada estranbo, já que uma das características de toda ideologia é, por intermédio de silêncios, inversóes e mudanças de ênfase, incorporar contradiçóes sem se perceber.

Oprojeto de uma educação total, que incluía bigiene, comportamento, recreação e ensino formal tinba o objetivo de fazer o que a família não vinha conseguindo: formar pessoas capazes de trabalhar em grupo, unificadas por ideais de coletividade que inchuíam todos, apesar de suas diferenças sociais, em favor de um objetivo maior: a construção da Nação. Assim, cada um cumpriria o seu papel, tendo por base aquela infância bem formada, tanto física como "moralmente".

Havia complicadores diante do discurso do Departamento. O maior deles talvezfosse a pobreza. Seus médicos acreditavam que uma educaçấo correta das máes resolveria boa parte dos problemas de nutrição das crianças, mas nunca incorporaram uma preocupação sistemática sobre como as mães conseguiriam os alimentos. Este problema, no entanto, existia e náo podia ser ignorado. Daí algumas iniciativas sempre inchúrem mecanismos

188 assistencialistas mais tradicionais, como a doaçáo de leite ou alimentos. De qualquer forma, isto era sempre visto como suplemento do programa. Se bouvesse pobreza, que fosse auxiliada, mas a tarefa principal náo era concebida como sendo esta.

ODNCr organizou, durante o Estado Novo, várias comemorações na semana em que caía o dia da criança, época em que vinba a público, de maneira organizada e com grande investimento propagandístico para apresentar suas idéias. Náo bavia interlocutores em condiçóes de fazer críticas e apresentar alternativas. Mesmo assim, oprograma permaneceria, em linhas gerais, o mesmo nos anos que se seguiriam à queda de Vargas, perdendo seus aspectos ideológicos mais salientes e se reduzindo à prática da assistência nos Postos de Puericultura. Oque interessa aqui é que seus componentes ideológicos básicos pertenciam a uma tradição também reconbecida no Brasil. Ocorre que o Departamento fez uma leitura conservadora deles, aproveitando-se da situação privilegiada de atuar em um instante de fechamento político. Sem fugir a uma característica geral do Estado Novo, porém, os médicos puericultores souberam construir uma mensa- 
gem positiva para que ela ocupasse olugar de outra. O regime fez isto com relaçáo a o mundo do trabalbo ${ }^{14}$ e conseguiu o mesmo no campo da assistência materno-infantil. O modelo dominante na República Vellha fora o de instituiçóes particulares, subsidiadaspelo Estado, voltadas para o apoio a mães e crianças pobres. ODNCr mudou o objeto da política para todas as mães e crianças. Para tanto, utilizou-se daquele antigo dualismo que endeusava a criança, só que com uma chave conservadora de leitura. Por outrolado, durante os anos 30, o movimento feminista chegou a questionar esta construção, apresentando uma leitura complemente diferente do tema. A comparação entre os dois é importante para que sejam demarcadas as esfercas de possibilidades existentes. Com esta intenção, apresento, em seguida, a proposta feminista.

\section{O DISCURSO FEMINISTA SOBRE A INFÂNCIA}

O Estado Novo foi responsável pelo silenciamento de forças políticas como o PCB, como o movimento negro ${ }^{15}$ e ofeminista ${ }^{16}$, atingidos pela repressáo, pelo fechamento do Congresso e pela propaganda oficial. Assim, é interessante abordar um projeto de lei, apresentado à Câmara dos Deputados pouco antes do golpe de 1937, o que selou seu destino, que pretendia criar o Departamento Nacional e o Conselbo Geral do Lar, Trabalbo Feminino, Previdência e Seguro Social. O projetofora longamente discutido na Comissáo de Estatuto da Mulber, que era presidida pela deputada Bertha Lutz. Seguindo determinaçóes do III Congresso Feminino Nacional, realizado em 1936, ela expôs à Comissão um primeiro texto, que criava o Departamento Nacional da Mulber. Ele foi criticado pelos deputados Prado Kelly e Carlota Pereira de Queiroz, com a conseqüente modificação de seu conteúdo.

Para Bertha Lutz, oDepartamento da Mulber tinba comofunção principal a fiscalização do trabalho das mulberes e das menores e a administraçáo do Seguro Maternal. Este era definido como um fundo, mantido pelo Estado, pelo empregador e pela empregada, que deveria prover o sustento da mulber na época da gravidez e do parto, de forma que ela pudesse se ausentar do trabalbo sem preocupação com o salário. 
O Departamento da Mulber também cuidaria da educação feminina, da preparação de pessoal técnico para as atividades de fiscalização e de "orientar e dirigir o amparoà maternidade, coordenando, fiscalizando e criando as instituiçóes necessárias para esse fim". Haveria, a seu lado, um Conselbo Nacional da Mulber, com o qual a repartição do MES dedicada à "assistência sanitária à mulber" (ou seja, o núcleo que viria formar o DNCr) deveria se articular. $O$ órgão, contudo, não era definido como uma pasta ministerial, nem como submetido diretamente à Presidência.

O projeto de Bertha Lutz, portanto, interferia diretamente nos projetos dos médicos puericultores do MES, que já vinbam sendo gestados. A simples existência de um órgão voltado para a mulber como trabalbadora, estando calcado numa relação corporativa com as associaçóes de mulberes - e não de "senboras"-representava competição equestionamento suficientes para o modelo do futuro DNCr.

No seu parecer, Prado Kelly defendeu a posição do MES, observando que os atos da administraçáogeral relativos ao amparo à 190 maternidade è̀ infância lhes eram relativos, de forma que o DepartamentodaMulher deveria seresumir a atribuiçóes fiscalizadoras e orientadoras. Carlota de Queiroz, em seguida, observou que a regulamentação do trabalbo não seria o maior problema da muIher: A educação e a saúde seriam mais importantes, o que justificaria a subordinaçáo do Departamento da Mulber aoMES, onde as questóes relativas à educação feminina seriam inchusas no plano geral de educação do país. Ela também sugeriu uma mudança de nome, para Departamento de Amparo à Mulher è̀ Criança, que seria o núcleo de um futuro Departamento de Assistência Social, responsável por todas as iniciativas assistenciais.

Lutz defendeu suas propostas, fazendo referências aos compromissos assumidos pelo Brasil perante a Organização Internacional do Trabalbo. Insistiu na necessidade do ensino feminino doméstico, que poderia incluir até o ensino superior de economia do la como capacitador da cidadania feminina, e criticou o modelo assistencialista e a situação de exploração da mão-deobrafeminina urbana: 
Pouco adianta a consulta gratuita em ambulatórios a pacientes que se acham desprovidas de meios de se locomoverem da casa ao hospital e de adquirirem os medicamentos receitados.

(...)

os problemas das mães pobres não tem solução adequada nem sequer na Capital do País. Diariamente batem elas Às portas da Câmara para exporem às Deputadas as condiçôes de miséria e de sofrimento em que renovam as gerações de brasileiros.

Após alguma negociação, decidiu-se submeter oDepartamento da Mulber ao controle do MTIC e não do MES e dividir seus poderes com um Conselbo Geral, composto por Conselbos Técnicos, algums anexos ao MTIC (do Lar, do Trabalbo Feminino e do Seguro Maternal e Previdência), e outros ao MES (da Educação Feminina Doméstica e Vocacional e o do Amparo Sanitário à Mãe e à Criança). ODepartamento e seu Seguro Maternal seriam sustentados pela cota constitucional de 1\% dasreceitas gerais, introduzida no texto de 1934, a ser dividida com o núcleo do MES (Divisão de Amparo à Maternidade è̀ Infância) que geraria oDNCr.

Não é possível saber se o projeto seria aprovado pelo Congresso Nacional, considerando as prováveis objeçôes do MES e o MTIC. Mesmo assim, um outro discurso foi engendrado e, sustentado por uma organização coletiva, apresentou-se para a sociedade. Mesmo que não vencesse o embate, tratava-se de uma outra visão. As feministas encaravam um público diferente: não mais as mães e crianças, mas as mulberes trabalbadoras. Oseu princípio unificador era uma noção de cidadania conquistada pela participação igualitária no mercado de trabalbo, não no sentido de que as mulberes desenvolvessem exatamente as mesmas atividades que os bomens, mas que, em sua especificidade, tivessem a oportunidade de desempenbo profissional. Isto significa, por exemplo, que as feministas reconbeciam o trabalbo doméstico como uma atividade feminina, o que não significa que ele não pudesse ser realizado por pessoas preparadas para isto, através de um processo educativo especúfico. Fica implícita a concepção de uma política social fundada no direito civil e não na caridade (conforme a visão mais antiga) ou no projeto conservador de unidade da familia (na visão dos médicos puericultores). 
Concluiu-se que no Estado Novo, constituiu-se em um programa de assistência à infância que produziu uma leitura conservadora de uma simbologia dualista sobre as crianças. Esta era, porém, apenas uma das possibilidades. Um discurso completamente novo foi capaz de emergir e se mobilizar para disputar o mesmo espaço. Não é possível medir até que ponto ele tinba apoio da Sociedade, mas tratava-se de um competidor. Ao ser silenciado, facilitou a ascensão da interpretação dos puericultores.

\section{UMA ALTERNATIVA DOMÉSTICA}

Calado o movimento feminista, os médicos do DNCr viramse, pelo menos uma vez, questionados em seu modelo. Trata-se de um relatório feito pelo sociólogo Alberto Guerreiro Ramos, que trabalhava nos quadros docentes dos cursos preparatórios do próprio Departamento. Ele não só dava aulas de sociologia aos médicos, como interpretava dados levantados pelos técnicos. Nestas circunstâncias, teve acesso a pesquisas, por exemplo, sobre a populaçáo favelada do Rio de Janeiro, onde se verificava a 192 alta incidência de emprego, mas com pequeno ganbo salarial, o que desmentia a visão tradicional sobre estes contingentes como “desocupados”. Assim, ele propôs novas interpretaçóes aos médicos do Departamento.

Para Guerreiro Ramos, havia, no estudo das anomalias, três tipos de ambientes: o primitivo, o rural e o urbano. O que os diferenciava era o processo de socialização e de integração dos indivíduos no grupo maior. Dessa maneira, nas sociedades primitivas, a socialização seria total, já que não haveria diferenças sócio-econômicas entre as pessoas. Nas sociedades rurais, todavia, introduzia-se alguma diferenciação, mas como a agricultura seria responsável por um alto grau de estabilidade familiar (pela posse da terra, divisáo do trabalbo, alianças etc) a socialização seria abrangente. Nas sociedades urbanas, por outrolado, as pessoas passariam a vivernum "meio artificial", onde os laços de solidariedade seriam substituídos pela impessoalidade e o individualismo. Aí, portanto, as anomalias seriam maiores, devido à interrupção de uma certa tendência para o equilíbrio social. 
Veja-se que, num sentido geral, a argumentação deslocava o problema do campo para a cidade, dando pouca importância a fatores "genéticos" e desconsiderando a questão da "falta de educação". Nas palavras de Guerreiro Ramos:

A mortalidade infantil, a mortalidade materna, a delinqüência juvenil e o menor abandonado são os problemas capitais que concernem à política do Departamento Nacional da Criança. Acreditamos ser da maior importância que os médicos puericultores se familiarizem com os estudos sociológicos sobre a cidade porque aqueles problemas estão intimamente relacionados com as condiçóes ambientais. A sociologia da cidade irá mostrar que não se deve dar excessiva ênfase a o aspecto biológico daqueles problemas. Eles são problemas sociais.

Logo, a atenção deveria se dirigir para os grandes centros urbanos. Por isso, os médicos precisariam conbecer os problemas das cidades, de forma a intervir onde fosse necessário. Este saber, segundo Guerreiro Ramos, baseava-se na metáfora biológica do organismo. A cidade seria como uma planta em crescimento. Tal qual um ser vivo, a cidade teria um metabolismo, onde predominariam os movimentos de eliminação (catabolismo) e de incorporação (anabolismo) de pessoas e valores. Na cidade, portanto, ocorreriam os seguintes processos: concentraçáo, centralização, segregação, invasão, sucessão, descentralização e rotinização.

Taisfenômenosteriam uma expressáogeográfica. Cada cidade possuiria quatro grandes áreas universais. Na Zona I, odistrito central de negócios, onde se dariam os processos de centralização e de concentração. Na Zona II, considerada de "transição provisória", predominariam as regióes decadentes, invadidas pelas atividades da Zona I. Seria o lugar de residência das pessoas mais atingidas pela desorganização efalta de solidariedade. AZona III seria mais estável, constituída pelos bairros habitacionais de classe média. AZona IV seria a suburbana, onde a influência do meiorural seriamaior.

Os problemas mais significativos se localizariam, portanto, na Zona II, a dos bairros pobres e favelas, onde conviviriam a prostituição, a delinqüência juvenil, a vadiagem, a mortalidade infantil e materna. Assim, os médicos deveriam identificar tais áreaseagirnelas: 
As causas da mortalidade infantil, da mortalidade materna, da delinqüência juvenil e do abandono do menor não são apenas biológicas. OPosto de Puericultura, a Maternidade, a visita domiciliar do médico e da enfermeira são, certamente, poderosos instrumentos de luta contra aqueles males, mas bá outras faces do problema que devem ser consideradas. Existem na cidade focos de mortalidade infantil e materna, focos de delinqüência juvenil. A resolução do problema requer não só o tratamento dos indivíduos como a modificação dos ambientes. A mortalidade infantile a materna são máximas nas classes de baixo núvel econômico. A desnutrição materna, o trabalbo materno, a falta de assistência médica, a babitação em comum em ambientes anti-bigiênicos, decorrentes do baixo padrão de vida são causa importantíssimas daquelesmales.

A ação, diante disso, deveria se dar da seguinte maneira: 1) localização, em cada foco, de Postos de Puericultura e Maternidades; 2) construção, em cada foco, de babitaçôes bigiênicas; 3) localização, em cada foco, de restaurantes populares. Com isso, Guerreiro Ramos não discordava dos meios propostos no programa do DNCr, mas os dirigia especificamente para a população pobre. Ele náo fazia qualquer menção a um projeto mobilizador. Pelo contrário, a ação estatal direta seria essencial:

(...) o maior obstáculo à realização de um plano pluridimensional dos serviços de puericultura náo é devido à ausência de pessoal babilitado e de dirigentes capazes, mas à extensáo do campo do DNCr è̀ falta de verbas suficientes.

Dessa forma, a burocracia do Departamento teve em suas mãos não só dados como também uma interpretação "cientificamente orientada" em favor de uma política de fundo estatal e diretamente voltada para a população traballbadora urbana. Mesmo assim, não incorporou tais elementos ou sequer tentou criticálos. As sugestóes de Guerreiro Ramosforam simplesmente ignoradas. Trata-se de um silêncio revelador: Afinal, a abordagem descrita, seguindo uma antiga tradição na sociologia, estava baseada em uma questão que também era candente para a abordagem do DNCr: a solidariedade grupal. Ocorre que, para Guerreiro Ramos, o retorno puro e simples a um estágio "comunal" seria impossível. Ele estava se referindo à sociedade, cujo contraponto só poderia ser o Estado, daí a necessidade de sua intervenção para, 
por meio de políticas compensatórias, eliminar os riscos da desgregaçáo e das anomalias produzidas pelo individualismo. Os médicos puericultores também desejavam o reforço da solidariedade, mas por um processo eminentemente conservador, no sentido original desta palavra, ou seja, voltado para o passado, quando a comunidade ideal, dirigida por uma elite responsável, estaria pronta para assumir suas responsabilidades perante "os de baixo". Daí o diagnóstico recuperar elementos simbólicos do séculoXVII, oque nos leva à conclusão.

\section{O DISCURSO NO TEMPO}

Em sua abordagem sobre a sociologia do conbecimento, Michael Löwy ${ }^{17}$ analisa o processo pela qual o positivismo surgiu como uma ideologia radical e questionadora da ordem estabelecida, no fim do século XVIII, até adquirir um perfil plenamente conservador na metade do XX, sob a batuta de Comte. Não é estranbo que discursos mudem de sentido ao longo do tempo. No caso citado, o autor relaciona a mudança com o processo de ascensão da burguesia. Oobjeto desse artigo não apresenta uma evolução tão sensacional, mas revela um jogo emblemático de interações. Em primeiro lugar, há um conjunto de elementos simbólicos que, de maneira resumida, produziram um endeusamento da figura da criança. Trata-se de um longo processo bistórico, que inseriu no nível das mentalidades coletivas, mesmo que de maneira dispersa, ideais e representaçóes sobre a infância que implicam em uma chave de leitura mediada pelo afeto. Uma criança não pode ou não deve ser encarada objetivamente, sem paixóes. Rousseau foi, provavelmente, o intelectual que melhor captou tais sentimentos, oferecendo-lhes uma leitura específica. Num momento bistórico de profundo trauma causado pelo advento da sociedade burguesa e de seus padróes típicos de relaçóes sociais, quando surgiram tantos exemplos de retorno a um passado idealizado, ofilósofo soube combinar as duas visóes, voltada para o passado, portanto, conservadora, baseada na metáfora dualista do Estado de Sociedade $x$ Estado de Natureza, com outra muito mais moderna e radical, que identificava a propriedade privada, quer dizer, o nexo fundamental do capitalismo, como a fonte de 
toda crise que se passava. A solução de Rousseau, portanto, associava afeto com liberdade. Em que pese seu conteúdo utópico, ela era progressista.

No Brasil do Estado Novo, a proteção materno-infantil fo $i$ pensada com recurso à mesma metáfora dualista, só que com um viés claramente conservador. Conseguiu, tantos anos depois, ocupar o lado oposto do espectro político. Uma primeira conclusão importante é que sentimentos e concepçóes de mundo arraigadas na longa duração podem ser manipulados e lidos de maneiras diversas, o que revela a existência daquele "tempo medianamente longo" de Vovelle, baseado no confronto de propostas. No caso específico aqui abordado, o DNCr, refletindo o projeto político do regime varguista, colocou-se contra o antigo discurso assistencialista, guiado pela caridade para com mães pobres, em favor de uma abordagem que incluísse todas as mães e crianças. Esta expansão dos campos de ação da política social tinha raízes na longa evolução do pensamento autoritário, que ofereciajustificativas ideológicas para a intervençãodo Estadona tarefa de "cons-

196 trução da Nação”. Mesmo com esta conexão, os médicos do DNCr construíram uma abordagem que chegava até a entrar em contradição com outros aspectos importantes da ação governamental, como a valorização do trabalho em geral, inclusive ofeminino. Eu não tratei aqui das razóes eminentemente políticas que levaram a este resultado. O que importa é que o discurso produzido reelaborou toda uma simbologia inscrita na mentalidade coletiva. Seu mecanismo fundamental foi o de, retomando o dualismo, transformar a criança em objeto do afeto da mãe, que teria naturalmente esta capacidade, só interrompida pelo exercício do trabaIho. Desta forma, ao tornar a criança o centro da política, culpabilizou, de uma maneira eminentemente personalista, a mãe, apagando a imagem da traballbadora, além de exchir a figura do pai e, portanto, dotrabalhador.

O movimento feminista chegou a sustentar uma abordagem progressista do problema, quando inverteu os pólos e se concentrou na figura da trabalbadora, relegando a questão do afeto a um nível privado, e enfatizando os aspectos públicos da assistência materno-infantil. Na sua leitura, a mulher trabalhadora, imbu- 
ida de direitos de cidadania, deveria ter acesso a meios compensatórios geridos pelo Estado para garantir, ao mesmo tempo, sua condição de mãe e profissional inserida no mercado de traballbo.

O afeto, portanto, não é, necessariamente, elemento para um viés conservador sobre as dificuldades atinentes ao universo infantil. Mais ainda, a ingenuidade contida nas idéias dos médicos do Departamento, pelo menos, guarda uma utopia participativa que se perdeu. Ainda boje o dualismo é uma marca das reflexóes sobre a criança e seu antípoda demonizado, o menor, porém a leitura é eminentemente burguesa, no sentido da mercantilização das relações sociais. O passado mostra que é possível inverter sentidos, mesmo quando se trata de sentimentos arraigados na mentalidade coletiva.

\section{NOTAS}

${ }^{1}$ Agradeço ao parecerista anônimo da Revista Brasileira de História, que destacou a relevância do processo concreto que levou à formaçáo da citada política. Neste artigo, porém, optei por abordar as suas bases ideológicas, na medida em quejá analisei a implementaçãodo programa em PEREIRA, André R. "Criança $x$ Menor: a origem de dois mitos da politica social brasileira”. In ROLLEMBERG, Denise (org.). Que bistória é essa? Novos temas e novos problemas em bistória. Rio de Janeiro, Relume-Dumará, 1994, pp. 91-109.

${ }^{2}$ Ver ARIÈS, Philippe. História social da criança e da família. $2^{a}$ ed., Rio de Janeiro, LTC, 1981.

${ }^{3}$ Ver, por exemplo, BADINTER, Elisabeth. Um amor conquistado: o mito do amor materno. $8^{a}$ ed., Rio de Janeiro, Nova Fronteira, 1985.

${ }^{4}$ O que se segue é baseado em três livros de ROUSSEAU, Jean-Jacques. Discurso sobre a origem e os fundamentos da desigualdade entre os bomens. Brasília/ São Paulo, Edund/Ática, 1989; Emílio ou Da educação. $3^{a}$ ed., São Paulo, Difel, 1979; O contrato social. Sáo Paulo, Martins Fontes, 1977.

${ }^{5}$ Ver BENDIX, Reinbard. Construção nacional e cidadania: estudos de nossa ordem social em mudança. São Paulo, Edusp, 1996.

${ }^{6}$ Ver THOMPSON, E. P. Costumes em comum: estudos sobre a cultura popular tradicional. Sáo Paulo, Companbia das Letras, 1998.

${ }^{7}$ É algo que ainda existe, sem dúvida, mas perdeu muito do seu impacto.

${ }^{8}$ Para maiores detalhes, vero meu artigo citado acima.

${ }^{9}$ Ver VOVELLE, Michel. "A história e a longa duração” In LE GOFF,Jacques (org.). A nova bistória. $2^{a}$ ed., São Paulo, Martins Fontes, 1993, pp. 68-96.

${ }^{10}$ Daqui em diante reproduzo, com algumas modificaçóes, partes da minba dissertação de mestrado em bistória. Para não sobrecarregar o texto, nãofarei referências às fontes primárias. Qualquer dúvida, ver PEREIRA, André R. V. V. Políticas sociais e corporativismo no Brasil: o Departamento Nacional da Criança no Estado Novo. Mestrado em História. Niterói, ICHF/UFF, 1992. 
${ }^{11}$ Puericultura é o estudo do desenvolvimento físico, mental e moral da criança. Tecnicamente falando, estes médicos deveriam ser pediatras, mas sua identificaçáo com a puericultura demonstra a amplitude de seu interesse.

${ }^{12}$ Veradiante.

${ }^{13}$ Por uma questáo de espaço, não abordarei este assunto aqui.

${ }^{14}$ Ver GOMES, Angela C. A invenção do trabalhismo. São Paulo/Rio de Janeiro, Vértice/IUPERJ, 1988.

${ }^{15}$ Ver MOURA, Clóvis. Sociologia do negro brasileiro. São Paulo, Ática, 1988.

${ }^{16}$ Ver SOIHET, Rachel. Bertha Lutz e a ascensão social da mulher. 1919-1937. Mestrado em História. Niterói, ICHF/UFF, 1974.

${ }^{17}$ Ver LÖWY, Michael. As aventuras de Karl Marx contra o Barão de Münchbausen: marxismo e positivismo na sociologia do conbecimento. $5^{a}$ ed., Sáo Paulo, Cortez, 1994. 